Edo Rajh*

\author{
JEL Classification M30 \\ Prethodno priopćenje \\ https://doi.org/10.32910/ep.70.3.8
}

\title{
MJERNA LJESTVICA ZA MJERENJE TRŽIŠNE VRIJEDNOSTI ZEMLJE PORIJEKLA
}

Tržišna vrijednost zemlje porijekla je agregatni koncept koji kombinira dva zasebna teorijska koncepta - tržišnu vrijednost marke i zemlju porijekla. Cilj rada je razviti i testirati mjernu ljestvicu za mjerenje tržišne vrijednosti zemlje porijekla. $U$ radu je analizirana psihometrijska adekvatnost mjerne ljestvice te je procijenjena njezina pouzdanost, konvergentna i diskriminantna valjanost, te dimenzionalnost. Podaci su analizirani izračunom Cronbachovog alfa koeficijenta te eksplorativnom i konfirmativnom faktorskom analizom. Rezultati istraživanja upućuju na zaključak da mjerna ljestvica posjeduje zadovoljavajuće psihometrijske karakteristike. Razvijena mjerna ljestvica posjeduje svojstva pouzdanosti, konvergentne i diskriminantne valjanosti, a dimenzionalnost ljestvice je u skladu s konceptualiziranom dimenzionalnošću.

Ključne riječi: tržišna vrijednost marke, zemlja porijekla, tržišna vrijednost zemlje porijekla

\section{Uvod}

Koncepti tržišne vrijednosti marke i zemlje porijekla su bitni elementi suvremene teorije tržišnog poslovanja te su u znanstvenoj literaturi prisutna brojna istraživanja posvećena navedenim konceptima (npr. Bennett, Kozup i Taylor,

* Dr. sc. E. Rajh, znanstveni savjetnik, Ekonomski institut, Zagreb (E-mail: erajh@eizg.hr).

Rad je primljen u uredništvo 28.11.2018. godine, a prihvaćen je za objavu 10.01.2019. godine. 
2018; Chatzipanagiotou, Christodoulides, i Veloutsou, 2019; Chekalina, Fuchs i Lexhagen, 2018; Foroudi, Jin, Gupta, Foroudi i Kitchen, 2018; Van Esch, Northey, Duffy, Heller i Striluk, 2018). Ipak, vrlo je mali broj istraživanja koja kombiniraju ova dva koncepta (npr. Zeugner-Roth, Diamantopoulos i Montesinos, 2008; Herrero-Crespo, Gutiérrez i Garcia-Salmones, 2016), iako je u literaturi prepoznata njihova teorijska i praktična povezanost (npr. Shimp, Samiee i Madden, 1993; Pappu, Quester i Cooksey, 2006).

Ključni element povezanosti koncepata tržišne vrijednosti marke i zemlje porijekla je u činjenici da marke iz određene zemlje stvaraju skup asocijacija u svijesti potrošača koje se nakon toga povezuju i sa svim ostalim markama koje dolaze iz iste zemlje, te se na taj način stvara određena agregatna marka zemlje porijekla (Pappu, Quester i Cooksey, 2007). U tom kontekstu se može govoriti i o tržišnoj vrijednosti zemlje porijekla koja se pri tome povezuje s agregatnom markom zemlje porijekla.

Cilj rada je razviti mjernu ljestvicu za mjerenje tržišne vrijednosti zemlje porijekla te testirati njezine psihometrijske karakteristike - pouzdanost, konvergentnu i diskriminantnu valjanost, te njezinu dimenzionalnost. Istraživanjem je testirana sljedeća hipoteza: razvijena mjerna ljestvica posjeduje zadovoljavajuće psihometrijske karakteristike.

Rad se sastoji od pet poglavlja. Nakon uvodnog poglavlja, drugo poglavlje sadrži pregled relevantne znanstvene literature. U trećem poglavlju je opisana metodologija istraživanja, a u četvrtom su predstavljeni rezultati istraživanja. U posljednjem, petom poglavlju izneseni su zaključci istraživanja.

\section{Pregled literature}

Pod pojmom tržišne vrijednosti marke se u literaturi podrazumijeva kako financijska vrijednost marke kao nematerijalne imovine poduzeća, tako i skup asocijacija i ponašanja potrošača povezanih s markom, a koji omogućavaju stvaranje održivih konkurentskih prednosti (Srivastava i Schocker, 1991). Potrošački aspekt ovog fenomena se može promatrati s bihevioralnog stajališta i s kognitivnog stajališta. S bihevioralnog stajališta, tržišna vrijednost marke se promatra kao snaga povezanosti potrošača s određenom markom te se može definirati kao razlika u odabiru potrošača između markom označenog i neoznačenog proizvoda uz istu razinu ostalih obilježja proizvoda (Yoo, Donthu i Lee, 2000). S kognitivnog stajališta, tržišna vrijednost marke se sastoji u skupu asocijacije i uvjerenja koja potrošači vezuju uz pojedinu marku, te se definira kao diferencijalni učinak koji znanje o marki ima na odgovor potrošača marketingu marke (Keller, 1993). 
Tržišna vrijednost marke pruža brojne koristi poduzećima koja posjeduju marke. Tržišna vrijednost marke povećava vjerojatnost odabira marke, kao i vjerojatnost stvaranja lojalnosti potrošača (Pitta i Katsanis, 1995). Visoka tržišna vrijednost marke omogućava uspješno kreiranje proširenja marke na druge kategorije proizvoda (Aaker i Keller, 1990; Wu i Yen, 2007). Visoka tržišna vrijednost marke je povezana i s nižim troškovima oglašavanja i većom prodajom (Smith i Park, 1992). Također, tržišna vrijednost marke pozitivno utječe na spremnost potrošača da plate premijske cijene za marke, na uspješnost aktivnosti marketinške komunikacije, na elastičnost potrošača na smanjenje cijena, kao i na neelastičnost potrošača na povećanje cijena, te na smanjenu ranjivost poduzeća od marketinških aktivnosti konkurencije (Barwise, 1993; Farquhar, Han i Ijiri, 1991; Keller, 1993; Pitta i Katsanis, 1995; Simon i Sullivan, 1993; Yoo i sur., 2000).

Zemlja porijekla proizvoda ili marke predstavlja važan indikator za potrošače na temelju kojega formiraju percepciju o kvaliteti proizvoda (Insch i McBride, 2004; Usunier i Cestre, 2007; Kumara i Canhua, 2010; Johnson, Tian i Lee, 2016). Zemlja porijekla proizvoda utječe i na novčani iznos kojega su potrošači spremni platiti za proizvod, na percepciju poruka marketinške komunikacije, te na formiranje namjere kupovine (Verlegh, Steenkamp i Meulenberg, 2005; Koschate-Fischer, Diamantopoulos i Oldenkotte, 2012; Berry, Mukherjee, Burton i Howlett, 2015). U teorijskoj konceptualizaciji ovog pojma napravljen je pomak od promatranja zemlje porijekla kao jednodimenzionalnog koncepta, na razumijevanje njegove višedimenzionalnosti. Stoga se u teoriju osim generičkog pojma zemlje porijekla sve češće uvode i pojmovi poput zemlje proizvodnje, zemlje dizajna, zemlje sastavljanja i slično (Batra, Ramaswamy, Alden, Steenkamp i Ramachander, 2000; Chao, 2001; Hamzaoui i Merunka, 2006; Brodowsky, 1998).

Iako suvremena teorija tržišnog poslovanja prepoznaje teorijsku i praktičnu povezanost koncepata tržišne vrijednosti marke i zemlje porijekla (npr. HerreroCrespo i sur., 2016; Zeugner-Roth i sur., 2008; Pappu i sur., 2006), i nadalje su rijetka istraživanja koja se bave njihovim odnosom i integracijom. Nekoliko je pristupa povezivanju koncepata tržišne vrijednosti marke i zemlje porijekla u postojećoj znanstvenoj literaturi. Jedan pristup se odnosi na razmatranje procesa stvaranja agregatne marke zemlje porijekla pri čemu sve marke iz određene zemlje stvaraju skup asocijacija u svijesti potrošača koje se nakon toga transferiraju i na sve ostale marke koje dolaze iz iste zemlje (Pappu i sur., 2007; Rosenbloom i Haefner, 2009). Drugi pristup povezivanju ova dva koncepta se sastoji u promatranju zemlje porijekla kao jednog od brojnih elemenata kognitivnog pristupa tržišnoj vrijednosti marke (Keller, 1993; Samiee, Shimp i Sharma, 2005). I konačno, treći i najtemeljitiji pristup njihovog povezivanja se sastoji u pojmovnoj integraciji, pri čemu se zemlja porijekla u potpunosti promatra kroz teorijsku prizmu tržišne vrijednosti marke. U okviru posljednjeg pristupa dolazi do stvaranja novog teorijskog koncepta, koji se naziva tržišna vrijednost zemlje porijekla (Zeugner-Roth i sur., 2008). 
Tržišna vrijednost zemlje porijekla se definira kao dodana vrijednost koja nastaje zbog povezivanja proizvoda ili marke s određenom zemljom, a temelji se na percepciji potrošača (Zeugner-Roth i sur., 2008). S obzirom da tržišna vrijednost zemlje porijekla ovisi o individualnim percepcijama potrošača, ona se može znatno razlikovati od potrošača do potrošača, te u određenim situacijama može predstavljati ne samo znatan izvor konkurentskih prednosti nego i ozbiljnu opasnost od transfera negativnih asocijacija na znatan dio marki iz određene zemlje. Ovo također govori u prilog tome da se tržišna vrijednost zemlje porijekla može smatrati jednom od ključnih odrednica kupovnog ponašanja potrošača.

\section{Metodologija istraživanja}

Za potrebe testiranja mjerne ljestvice za mjerenje tržišne vrijednosti zemlje porijekla preuzete su pojedinačne tvrdnje iz postojeće znanstvene literature koja se bavi mjerenjem tržišne vrijednosti marke, te su prilagođene primjeni u novom kontekstu. Riječ je o sljedećim tvrdnjama (Yoo i sur., 2000):

- Ima smisla kupiti ovu marku umjesto neke druge čak i ako su te dvije marke iste,

- Ako se druga marka ni na koji način ne razlikuje od ove marke, ipak se čini pametnijim kupiti ovu marku,

- Čak i ako druga marka ima iste karakteristike kao ova marka, radije ću kupiti ovu marku,

- Ako bi postojala druga marka jednake kvalitete kao i ova marka, radije bih kupio/la ovu marku.

Prilagođene kontekstu tržišne vrijednosti zemlje porijekla, navedene tvrdnje glase kako slijedi:

- (t1) Ima smisla kupiti proizvod iz ove zemlje umjesto iz neke druge zemlje čak i ako su ta dva proizvoda ista,

- (t2) Ako se proizvod iz druge zemlje ni na koji način ne razlikuje od proizvoda iz ove zemlje, ipak se čini pametnijim kupiti proizvod iz ove zemlje,

- (t3) Čak i ako proizvod iz druge zemlje ima iste karakteristike kao proizvod iz ove zemlje, radije ću kupiti proizvod iz ove zemlje,

- (t4) Ako bi postojao proizvod iz druge zemlje jednake kvalitete kao i proizvod iz ove zemlje, radije bih kupio/la proizvod iz ove zemlje.

Za iskazivanje slaganja/neslaganja ispitanika s tvrdnjama primijenjena je Likertova ljestvica s pet stupnjeva (pritom je značenje brojeva bilo sljedeće: 1 uopće se ne slažem, 2 - ne slažem se, 3 - niti se slažem, niti se ne slažem, 4 - 
slažem se, 5 - u potpunosti se slažem). U istraživanju su obuhvaćene tri zemlje: Finska, Italija i Poljska. Navedene tri zemlje su odabrane zbog razlike u njihovim obilježjima, kako bi se povećala varijacija odgovora ispitanika. U analizi podataka su zanemarene zemlje za koje su ispitanici davali odgovore. Istraživanje je provedeno u razdoblju od ožujka do svibnja 2018. godine, na uzorku studenata Ekonomskog fakulteta Sveučilišta u Zagrebu. Konačan uzorak istraživanja je 450 ispitanika, po 150 ispitanika za svaku istraživanu zemlju.

Prikupljeni podaci su analizirani izračunom Cronbach alfa koeficijenta i primjenom eksplorativne i konfirmativne faktorske analize. Cronbach alfa koeficijent je pokazatelj pouzdanosti, odnosno interne konzistentnosti skupa tvrdnji koje čine mjernu ljestvicu, te kojima se mjeri ista latentna varijabla. Eksplorativna faktorska analiza je metoda multivarijatne statistike kojom se ispituje struktura odnosa između mjerenih varijabli, dok je konfirmativna faktorska analiza poseban oblik faktorske analize kojom se testiraju pretpostavljeni odnosi između manifestnih i latentnih varijabli (Hair, Black, Babin, Anderson i Tatham, 2006; Kline, 1998).

\section{Rezultati istraživanja}

Pouzdanost mjerne ljestvice je analizirana izračunom Cronbach alfa koeficijenta. Tablica 1 prikazuje rezultate analize pouzdanosti.

Tablica 1.

ANALIZA POUZDANOSTI - CRONBACH ALFA KOEFICIJENT

\begin{tabular}{|c|c|c|}
\hline Tvrdnje & Cronbach alfa ako se izostavi tvrdnja & Cronbach alfa \\
\hline $\mathrm{t} 1$ & 0,84 & \multirow{2}{*}{0,84} \\
\hline $\mathrm{t} 2$ & 0,81 & \\
\hline $\mathrm{t} 3$ & 0,78 & \\
\hline $\mathrm{t} 4$ & 0,73 & \\
\hline
\end{tabular}

Izvor: Istraživanje.

Rezultati upućuju na zadovoljavajuću razinu pouzdanosti mjerne ljestvice te ne postoji potreba za izostavljanjem pojedinih tvrdnji iz daljnje analize kako bi se povećala pouzdanost mjerne ljestvice.

Konvergentna i diskriminantna valjanost mjerne ljestvice su testirane primjenom eksplorativne i konfirmativne faktorske analize. Kao prvi korak u testiranju 
konvergentne i diskriminantne valjanosti provedena je eksplorativna faktorska analiza. Tablica 2 prikazuje rezultate eksplorativne faktorske analize.

\section{Tablica 2.}

\section{REZULTATI EKSPLORATIVNE FAKTORSKE ANALIZE}

\begin{tabular}{|c|c|}
\hline Tvrdnje & Faktorska opterećenja \\
\hline $\mathrm{t} 1$ & 0,72 \\
\hline $\mathrm{t} 2$ & 0,81 \\
\hline $\mathrm{t} 3$ & 0,86 \\
\hline $\mathrm{t} 4$ & 0,91 \\
\hline
\end{tabular}

Izvor: Istraživanje.

Sve tvrdnje mjerne ljestvice imaju visoka faktorska opterećenja na istom faktoru, što upućuje na zaključak da analizirana mjerna ljestvica posjeduje svojstva konvergentne i diskriminantne valjanosti. Također, rezultati eksplorativne faktorske analize upućuju da je mjerna ljestvica jednodimenzionalna. Dobivena faktorska struktura objašnjava $68 \%$ ukupne varijance.

Sljedeći korak u testiranju konvergentne i diskriminantne valjanosti mjerne ljestvice je provođenje konfirmativne faktorske analize, koja predstavlja stroži test konvergentne i diskriminantne valjanosti. Konfirmativnom faktorskom analizom testiran je mjerni model u kojem je specificirano da svaka manifestna varijabla opterećuje samo jednu latentnu varijablu. Tablica 3 prikazuje rezultate konfirmativne faktorske analize.

\section{Tablica 3 .}

\section{REZULTATI KONFIRMATIVNE FAKTORSKE ANALIZE}

\begin{tabular}{|c|c|}
\hline Tvrdnje & Standardizirana faktorska opterećenja \\
\hline $\mathrm{t} 1$ & $0,54^{*}$ \\
\hline $\mathrm{t} 2$ & $0,67^{*}$ \\
\hline $\mathrm{t} 3$ & $0,60^{*}$ \\
\hline $\mathrm{t} 4$ & $0,83^{*}$ \\
\hline
\end{tabular}

*statistički signifikantno na razini p<0,01; GFI: 0,984; AGFI: 0,919; NFI: 0,982; NNFI: 0,953; CFI: 0,984

Izvor: Istraživanje.

Vrijednosti indeksa odgovaranja mjernog modela empirijskim podacima (GFI, AGFI, NFI, NNFI, CFI) upućuju na zaključak da je razina odgovaranja 
definiranog mjernog modela empirijskim podacima zadovoljavajuća te da je definirani model prihvatljiv za daljnju analizu. Rezultati konfirmativne faktorske analize pokazuju da sve analizirane tvrdnje značajno opterećuju pridruženu latentnu varijablu te se može zaključiti da analizirana mjerna ljestvica posjeduje svojstva konvergentne i diskriminantne valjanosti. Također, rezultati konfirmativne faktorske analize upućuju na zaključak da je mjerna ljestvica jednodimenzionalna.

\section{Zaključak}

Koncepti tržišne vrijednosti marke i zemlje porijekla su bitni elementi suvremene teorije tržišnog poslovanja, te se teorijskom razradom njihovog međuodnosa i povezanosti mogu dobiti važne spoznaje o izvorima konkurentskih prednosti na međunarodnom tržištu. Jedan od mogućih pristupa teorijskog agregiranja dva navedena koncepta je stvaranje koncepta tržišne vrijednosti zemlje porijekla.

U radu je razvijena i testirana mjerna ljestvica za mjerenje tržišne vrijednosti zemlje porijekla. Testirana mjerna ljestvica posjeduje zadovoljavajuća psihometrijska obilježja. Rezultati istraživanja upućuju na zaključak da testirana mjerna ljestvica posjeduje svojstva pouzdanosti, konvergentne i diskriminantne valjanosti i jednodimenzionalnosti. Time je potvrđena hipoteza istraživanja te je ispunjen cilj rada. Također, nalazi istraživanja su u skladu s prethodnim istraživanjem kojim je razvijena osnovna mjerna ljestvica za mjerenje tržišne vrijednosti marke u kontekstu fizičkih proizvoda (Yoo i sur., 2000).

U razmatranju rezultata istraživanja treba imati na umu i određena ograničenja samog istraživanja. U prvom redu treba imati na umu da je istraživanje provedeno na uzorku studenata, što u određenoj mjeri može utjecati na ograničenu mogućnost generaliziranja nalaza istraživanja. U svrhu daljnjeg testiranja mjerne ljestvice moguće je provesti istraživanja na nekim drugim populacijama. Također, jedan od mogućih izvora ograničenja nalazi se u istraživanim zemljama. U istraživanju su obuhvaćene tri zemlje - Finska, Italija i Poljska, te je u svrhu daljnjeg generaliziranja rezultata istraživanja i daljnjeg testiranja mjerne ljestvice potrebno provesti dodatna istraživanja koja bi obuhvatila i druge zemlje.

Testirana ljestvica za mjerenje tržišne vrijednosti zemlje porijekla može poslužiti u budućim znanstvenim istraživanjima koja se bave tematikom uloge zemlje porijekla i marke na međunarodnom i domaćem tržištu. Također, mjerna ljestvica može poslužiti i u primijenjenim istraživanjima kojima je cilj istražiti probleme vezane uz konkretno poslovanje na međunarodnom tržištu. Isto tako, razvijena mjerna ljestvica može imati i praktičnu primjenu kao analitički alat u procesu upravljanja imidžom zemlje uz korištenje tehnika upravljanja markom. 


\section{Literatura:}

Aaker, D.A. i Keller, K.L. (1990). Consumer Evaluations of Brand Extensions. Journal of Marketing, 54(1), 27-41.

Barwise, P. (1993). Brand equity: snark or boojum? International Journal of Research in Marketing, 10(1), 93-104.

Batra, R., Ramaswamy, V., Alden, D.L., Steenkamp, J.B.E.M. i Ramachander, S. (2000). Effects of brand local and nonlocal origin on consumer attitudes in developing countries. Journal of Consumer Psychology, 9(2): 83-95.

Bennett, A.M., Kozup, J. i Taylor, C.R. (2018). Country-of-Origin Effects and Consumer Evaluations of Ads Within the Context of Economic Crises. Journal of Current Issues \& Research in Advertising, 39(1), 52-66.

Berry, C., Mukherjee, A., Burton, S. i Howlett, E. (2015). A COOL effect: The direct and indirect impact of country-of-origin disclosures on purchase intentions for retail food products. Journal of Retailing, 91(3), 533-542.

Brodowsky, G.H. (1998). The effects of country of design and country of assembly on evaluative beliefs about automobiles and attitudes toward buying them: A comparison between low and high ethnocentric consumers. Journal of International Consumer Marketing 10(3), 85-113.

Chao, P. (2001). The moderating effects of country of assembly, country of parts, and country of design on hybrid product evaluations. Journal of Advertising, 30(4), 67-81.

Chatzipanagiotou, K., Christodoulides, G. i Veloutsou, K. (2019). Managing the consumer-based brand equity process: A cross-cultural perspective. International Business Review, 28(2), 328-343.

Chekalina, T., Fuchs, M. i Lexhagen, M. (2018). Customer-Based Destination Brand Equity Modeling: The Role of Destination Resources, Value for Money, and Value in Use. Journal of Travel Research, 57(1), 31-51.

Farquhar, P.H., Han, J.Y. i Ijiri, Y. (1991). Recognizing and Measuring Brand Assets. Cambridge: Marketing Science Institute.

Foroudi, P., Jin, Z., Gupta, S., Foroudi, M.M. i Kitchen, P.J. (2018). Perceptional Components of BrandEquity: Configuring the Symmetrical and Asymmetrical Paths to Brand Loyalty and Brand Purchase Intention. Journal of Business Research, 89(1), 462-474.

Hair, J.F., Black, B., Babin, B., Anderson, R.E. i Tatham, R.L. (2006). Multivariate Data Analysis. New Jersey: Prentice Hall.

Hamzaoui, L. i Merunka, D. (2006). The impact of country of design and country of manufacture on consumer perceptions of bi-national products' quality: An 
E. RAJH: Mjerna ljestvica za mjerenje tržišne vrijednosti zemlje porijekla

empirical model based on the concept of fit. Journal of Consumer Marketing, 23(3), 145-155.

Herrero-Crespo, A., Gutierrez, H.S.M. i Garcia-Salmones, M.D.M. (2016). Influence of country image on country brand equity: application to higher education services, International Marketing Review, 33(5), 691-714.

Insch, G.S. i McBride, J.B. (2004). The impact of country-of-origin cues on consumer perceptions of product quality: A binational test of the decomposed country-of-origin construct. Journal of Business Research, 57(3), 256-265.

Johnson, Z.S., Tian, Y. i Lee, S. (2016). Country-of-origin fit: When does a discrepancy between brand origin and country of manufacture reduce consumers' product evaluations?. Journal of Brand Management, 23(4), 403-418.

Keller, K.L. (1993). Conceptualizing, Measuring, and Managing Customer-Based Brand Equity. Journal of Marketing, 57(1), 1-22.

Kline, R.B. (1998). Principles and Practice of Structural Equation Modeling. New York: The Guilford Press.

Koschate-Fischer, N., Diamantopoulos, A. i Oldenkotte, K. (2012). Are consumers really willing to pay more for a favorable country image? A study of country-of-origin effects on willingness to pay. Journal of International Marketing, 20(1), 19-41.

Kumara, S. i Canhua, K. (2010). Perceptions of country of origin: An approach to identifying expectations of foreign products. Journal of Brand Management, 17(5), 343-353.

Pappu, R., Quester, P.G. i Cooksey, R.W. (2006). Consumer-Based Brand Equity and Country-of-Origin Relationships. European Journal of Marketing, 40(5/6), 696-717.

Pappu, R., Quester, P.G. i Cooksey, R.W. (2007). Country Image and ConsumerBased Brand Equity: Relationships and Implications for International Marketing. Journal of International Business Studies, 38(5), 726-745.

Pitta, D.A. i Katsanis, L.P. (1990). Understanding brand equity for successful brand extension. Journal of Consumer Marketing, 12(4), 51-64.

Rosenbloom, A. i Haefner, J.E. (2009). Country-of origin effects and global brand trust: A first look. Journal of Global Marketing, 22(4), 267-278.

Samiee, S., Shimp, T.A. i Sharma, S. (2005). Brand origin recognition accuracy: Its antecedents and consumers' cognitive limitations. Journal of International Business Studies, 36(4), 379-397.

Shimp, T.A., Samiee, S. i Madden, T.J. (1993). Countries and Their Products: A Cognitive Structure Perspective. Journal of the Academy of Marketing Science, 21(4), 323-330. 
Simon, C.J. i Sullivan, M.W. (1993). The Measurement and Determinants of Brand Equity: A Financial Approach. Marketing Science, 12(4), 28-52.

Smith, D.C. i Park, C.W. (1992). The Effects of Brand Extensions on Market Share and Advertising Efficiency. Journal of Marketing Research, 29(3), 296-313.

Srivastava, R. i Schocker, A.D. (1991). Brand Eguity: A Perspective on Its Meaning and Measurement. Cambridge: Marketing Science Institute.

Usunier, J.C. i Cestre, G. (2007). Product ethnicity: Revisiting the match between products and countries. Journal of International Marketing, 15(3), 32-72.

Van Esch, P., Northey, G., Duffy, S., Heller, J. i Striluk, M. (2018). The Moderating Influence of Country of Origin Information Seeking on Homophily and Product Satisfaction. Journal of Promotion Management, 24(3), 332-348.

Verlegh, P.W.J., Steenkamp, J.E.M. i Meulenberg, M.T.G. (2005). Country-oforigin effects in consumer processing of advertising claims. International Journal of Research in Marketing, 22(2), 127-139.

Wu, C. i Yen, Y.C. (2007). How the strength of parent brand and associations influence the interaction effects of brand and breadth and product similarity with brand and extension evaluations. Journal of Product and Brand and Management, 16(5), 334-341.

Yoo, B., Donthu, N. i Lee, S. (2000). An Examination of Selected Marketing Mix Elements and Brand Equity. Journal of the Academy of Marketing Science, 28(2), 195-211.

Zeugner-Roth, K.P., Diamantopoulos, A. i Montesinos, A. (2008). Home Country Image, Country Brand Equity and Consumers' Product Preferences: An Empirical Study. Management International Review, 48(5), 577-602.

\section{A SCALE FOR MEASURING COUNTRY BRAND EQUITY}

Summary

Country brand equity is an aggregated concept that combines two separate theoretical concepts - brand equity and country of origin. The aim of the paper is to develop and to test measurement scale for measuring country brand equity. Psychometric adequacy of the measurement scale was analyzed by assessing reliability, convergent and discriminant validity and dimensionality of the measurement scale. The Cronbach alpha coefficient and explorative and confirmative factor analysis were applied. Results indicate that the measurement scale has satisfactory psychometric characteristics. The measurement scale possesses characteristics of reliability, convergent and discriminant validity, and its dimensionality fits the conceptualized dimensionality.

Key words: brand equity, country of origin, country brand equity 